\title{
Regional Dynamic and Steric Sea Level Change in Response to the IPCC-A1B Scenario
}

\author{
Felix W. Landerer, Johann H. Jungclaus, and Jochem Marotzke \\ Max Planck Institute for Meteorology, Hamburg, Germany
}

(Manuscript received 29 July 2005, in final form 6 February 2006)

\begin{abstract}
This paper analyzes regional sea level changes in a climate change simulation using the Max Planck Institute for Meteorology (MPI) coupled atmosphere-ocean general circulation model ECHAM5/MPI-OM. The climate change scenario builds on observed atmospheric greenhouse gas (GHG) concentrations from 1860 to 2000, followed by the International Panel on Climate Change (IPCC) A1B climate change scenario until 2100; from 2100 to 2199, GHG concentrations are fixed at the 2100 level. As compared with the unperturbed control climate, global sea level rises $0.26 \mathrm{~m}$ by 2100 , and $0.56 \mathrm{~m}$ by 2199 through steric expansion; eustatic changes are not included in this simulation. The model's sea level evolves substantially differently among ocean basins. Sea level rise is strongest in the Arctic Ocean, from enhanced freshwater input from precipitation and continental runoff, and weakest in the Southern Ocean, because of compensation of steric changes through dynamic sea surface height (SSH) adjustments. In the North Atlantic Ocean (NA), a complex tripole SSH pattern across the subtropical to subpolar gyre front evolves, which is consistent with a northward shift of the NA current. On interannual to decadal time scales, the SSH difference between Bermuda and the Labrador Sea correlates highly with the combined baroclinic gyre transport in the NA but only weakly with the meridional overturning circulation (MOC) and, thus, does not allow for estimates of the MOC on these time scales. Bottom pressure increases over shelf areas by up to $0.45 \mathrm{~m}$ (water column equivalent) and decreases over the Atlantic section in the Southern Ocean by up to $0.20 \mathrm{~m}$. The separate evaluation of thermosteric and halosteric sea level changes shows that thermosteric anomalies are positive over most of the World Ocean. Because of increased atmospheric moisture transport from low to high latitudes, halosteric anomalies are negative in the subtropical NA and partly compensate thermosteric anomalies, but are positive in the Arctic Ocean and add to thermosteric anomalies. The vertical distribution of thermosteric and halosteric anomalies is highly nonuniform among ocean basins, reaching deeper than $3000 \mathrm{~m}$ in the Southern Ocean, down to $2200 \mathrm{~m}$ in the North Atlantic, and only to depths of $500 \mathrm{~m}$ in the Pacific Ocean by the end of the twenty-first century.
\end{abstract}

\section{Introduction}

The relative sea surface height (SSH) directly reflects the three-dimensional, large-scale ocean circulation. On time scales exceeding a few days and length scales larger than $50 \mathrm{~km}$, theory shows that the SSH adjusts to the motions in the deep layers (Wunsch and Stammer 1998). From the viewpoint of classical oceanography, dynamic SSH is equal to depth-integrated specific volume anomalies (when referring to dynamic SSH, we tacitly assume that the geopotential units of meters squared per second have been converted to geometric

Corresponding author address: Felix W. Landerer, Max Planck Institute for Meteorology, Bundesstr.53, D-20146 Hamburg, Germany.

E-mail: felix.landerer@zmaw.de distance). The attribute "dynamic" refers to the geostrophic balance between horizontal flow and SSH gradients, or, equivalently, pressure gradients, such that the flow is parallel to contours of equal SSH (Gill 1982). In most regions of the World Ocean, the horizontal pressure gradients do not extend to the ocean bottom; they vanish at some depth because of density compensation, and cause an inverse correlation between SSH and pycnocline depth: a high sea level indicates a deep pycnocline, and vice versa. SSH changes can equivalently be interpreted in terms of the integral response to anomalies of the vertical density distribution (through temperature and salinity variations), in which case the attribute steric is commonly applied to describe these changes. We use the term "steric" here strictly as pertaining to the temperature, salinity, and pressuredependent specific volume of the ocean.

DOI: $10.1175 / \mathrm{JPO} 3013.1$

(C) 2007 American Meteorological Society 
The two perspectives on sea level changes-dynamic and steric - are intimately linked: a local change in the density distribution through temperature and salinity anomalies will alter the horizontal pressure gradients and therefore will be balanced by geostrophic velocity anomalies. Large-scale circulation changes, on the other hand, may redistribute characteristic water masses and, thus, lead to different steric sea level changes regionally.

One of the most striking features of the present-day sea surface topography is the low sea level in the North Atlantic Ocean relative to the North Pacific Ocean (Reid 1961; Rio and Hernandez 2004), a result of the denser deep water formed in the North Atlantic as part of the Atlantic meridional overturning circulation (MOC). If this deep-water formation rate was decreased or if the deep water formed became less dense, sea level rise in the North Atlantic region would be expected to be stronger than the global average (Levermann et al. 2005). Since SSH reflects the thermohaline structure and the strength of ocean gyres, it might then be possible to use altimetric SSH observations to assess the state and transport strength of the Atlantic MOC (Häkkinen 2001). Observations of SSH anomalies from space have been analyzed in connection with heat content changes in the North Atlantic (Häkkinen 2001; Antonov et al. 2005), the North Atlantic Deep Water (NADW) formation rate, and the strength of the thermohaline part of the MOC (Häkkinen 2001). However, detecting MOC changes through SSH measurements depends on the magnitudes and time scales of all adjustment processes that influence $\mathrm{SSH}$ in a climate change scenario. Mechanisms that influence regional SSH changes have been alluded to in a number of model studies (e.g., Mikolajewicz et al. 1990; Bryan 1996; Knutti and Stocker 2000; Mikolajewicz and Voss 2000; Gregory et al. 2001; Levermann et al. 2005), but the spatial patterns of predicted SSH changes by various models are still inconsistent with each other (Gregory et al. 2001). Thus, there is still considerable need to understand the physical processes behind regional SSH changes to put model differences into perspective. In particular, it is important to understand the connection between SSH variations and important climate indices, such as the transport strength of the Atlantic MOC.

Variations of regional SSH caused by a redistribution of water masses and ocean circulation changes have a near-zero global mean (minor variations arise only from nonlinearity in the equation of state). Global sea level rises when the absolute mass of the ocean water is increased (eustatic sources), through variations of the global mean salinity (which depends on eustatic sources, with the exception of melting sea ice), or when the specific volume is modified through net heating or cooling. The ocean heat content would change as a result of a planetary energy imbalance (Levitus et al. 2000). The issue of global sea level rise has received considerable attention in the last decade (e.g., Gregory et al. 2001; Antonov et al. 2002; Munk 2002; Cazenave and Nerem 2004; Antonov et al. 2005). There is, on the other hand, still a lot of uncertainty about the causes of observed global sea level change. This "enigma" (Munk 2002) relates to the many unknowns, which introduce large uncertainties in the calculation of a relatively small number. A rise due to ocean warming for the period 1993-2003 has been estimated at $1.6 \mathrm{~mm} \mathrm{yr}^{-1}$ for the upper $3000 \mathrm{~m}$ of the World Ocean, whereas measurements from satellite altimetry suggest an increase of $3.1 \mathrm{~mm} \mathrm{yr}^{-1}$ for the same period (Antonov et al. 2005), leaving a residual of $1.5 \mathrm{~mm} \mathrm{yr}^{-1}$ to be accounted for by nonthermosteric effects. Assuming a constant or near-constant global mean salinity, halosteric sea level changes are of second order globally, but can be very important regionally because of anomalous freshwater fluxes (Antonov et al. 2002). Interannual to decadal variability of local and global rates of sea level change are significant (Willis et al. 2004; White et al. 2005; Church et al. 2005) and complicate the detection of trends. Gregory et al. (2004) have pointed out, however, that the amplitude of this variability is possibly very sensitive to the treatment of data uncertainties in sparsely sampled regions.

The present study focuses on the analysis of simulated regional sea level changes in response to the International Panel on Climate Change (IPCC) A1B scenario (Houghton et al. 2001) from two perspectives. First, sea level is analyzed in terms of relative, dynamic SSH changes, and the connection of these regional and interbasin SSH adjustments to important oceanic transport indices, such as the MOC and the baroclinic gyre transport in the North Atlantic. Second, we calculate SSH changes due to steric effects from temperature and salinity anomalies, estimating the influence of each property separately on a regional basis, and also with respect to the steric contribution from each depth layer for different ocean basins. These results then provide a reference estimate of regional thermosteric and halosteric sea level anomalies in connection to largescale ocean circulation changes in a realistic climate change simulation. Decadal heat storage variability through volcanic aerosol forcing (Church et al. 2005) and the contribution of eustatic sources (glacial melting and land storage) are not taken into account in our simulation. The simulations were performed using the fully coupled atmosphere-ocean circulation model 
ECHAM5/MPI-OM developed at the Max Planck Institute for Meteorology (MPI).

The paper is organized as follows. In section 2 , we describe the main features of the coupled model, the mean state of the model's SSH in comparison with observations, and the climate scenario that was used for the perturbation simulation. Section 3 focuses on the spatial patterns of sea level change, and the link of these to large-scale circulation changes, such as the reduction of the Atlantic MOC and the North Atlantic baroclinic gyre transport. In section 4 , we analyze steric sea level changes, and calculate the bottom pressure anomalies and the contribution of temperature- and salinity-induced steric changes separately. Conclusions are given in section 5 .

\section{Model description, mean state, and scenario response}

\section{a. The ECHAM5/MPI-OM coupled model}

Our analysis uses results from climate change simulations that are performed with the coupled ECHAM5/ MPI-OM atmosphere-ocean general circulation model. The ocean component MPI-OM uses an orthogonal curvilinear grid with its North Pole shifted to Greenland to avoid a singularity at the geographical North Pole. The vertical resolution is $40 \mathrm{z}$ levels, 20 of which are distributed over the upper $700 \mathrm{~m}$; partial grid cells resolve the bottom topography. Horizontally, the resolution gradually varies between $12 \mathrm{~km}$ near Greenland and $180 \mathrm{~km}$ in the tropical Pacific. MPI-OM (Marsland et al. 2003) is coupled to the ECHAM5 atmosphere model (Roeckner et al. 2003) at T63 resolution with 31 vertical levels; no flux adjustments are applied. A dynamic-thermodynamic sea ice model with viscousplastic rheology is embedded in MPI-OM. More details on the ocean model formulation can be found in Marsland et al. (2003) and Jungclaus et al. (2006). Here, we focus on some main features of MPI-OM that are pertinent for the following analysis. MPI-OM uses a prognostic free-surface formulation for the calculation of the SSH $\zeta$. The vertically integrated continuity equation in the Boussinesq approximation reads

$$
\frac{\partial \zeta}{\partial t}+\frac{\partial U}{\partial x}+\frac{\partial V}{\partial y}=Q_{\zeta}(x, y)=P-E+R,
$$

where $U$ and $V$ are vertically integrated zonal and meridional flows, respectively. The forcing term $Q_{\zeta}(x, y)$ represents the surface freshwater flux due to precipitation $(P)$, evaporation $(E)$, and river runoff $(R)$. River discharge is calculated from the hydrological discharge model from Hagemann and Dümenil (1998), with the limitation that the melting of land ice is not considered, effectively excluding eustatic sources in the simulations. To close the mass balance over glaciers, snowfall onto the glaciers is redistributed to the nearest ocean point immediately. At time steps of 1 month, the prognostic $\mathrm{SSH}$ field is recentered to a zero global mean. The continuity Eq. (1) implies volume conservation (Gill 1982) in the ocean; this formulation yields correct relative horizontal SSH gradients, but a spatially uniform time-varying correction term must be applied in order to adjust the sea level for any net expansion or contraction through changes in the local density structure (Greatbatch 1994). This term is commonly referred to as the steric sea level effect. More precisely, given that $Q_{\zeta}$ is close to zero when averaged over the global oceans, and that eustatic mass sources are excluded, the global mean salinity will be constant and any net global volume change will be due to changes in ocean temperature only. For its central role in the force balance of geostrophic surface flow, we will refer to the sea level pattern relative to a zero global mean as dynamic SSH.

\section{b. Model mean state}

An unperturbed control simulation is forced with preindustrial greenhouse gas concentrations and serves as a reference for the calculation of changes in ocean circulation and sea level. A detailed description of the general model's behavior in terms of comparison with observed ocean properties can be found in Jungclaus et al. (2006). Here, we focus on the processes that control and influence the sea surface topography, both in terms of relative $\mathrm{SSH}$ gradient changes and changes of the global mean. The control simulation exhibits a global mean sea level drift of about $0.4 \mathrm{~mm} \mathrm{yr}^{-1}$ due to a slow warming of intermediate and deep waters (Jungclaus et al. 2006), which is mainly due to insufficient Antarctic Bottom Water (AABW) formation with correct water mass properties in the model (Jungclaus et al. 2006). The cold AABW cell weakens in the control simulation, thus causing a relative warming of these waters. The ACC region, consistently, experiences a small positive dynamic SSH drift of $\approx 0.15 \mathrm{~mm} \mathrm{yr}^{-1}$. In comparison, the drift of the dynamic SSH field in the other ocean basins is at least an order of magnitude smaller (not shown). As we will show in section 3, the relative regional SSH changes due to greenhouse gas (GHG) forcing are one to two orders of magnitude larger than any control simulation drift. We thus consider the model's mean dynamic SSH pattern as sufficiently stable in time and use it as a reference for the computation of anomalies.

The Combined Mean Dynamic Topography (CMDT) dataset (Fig. 1a), which is derived from satellite altim- 
a)

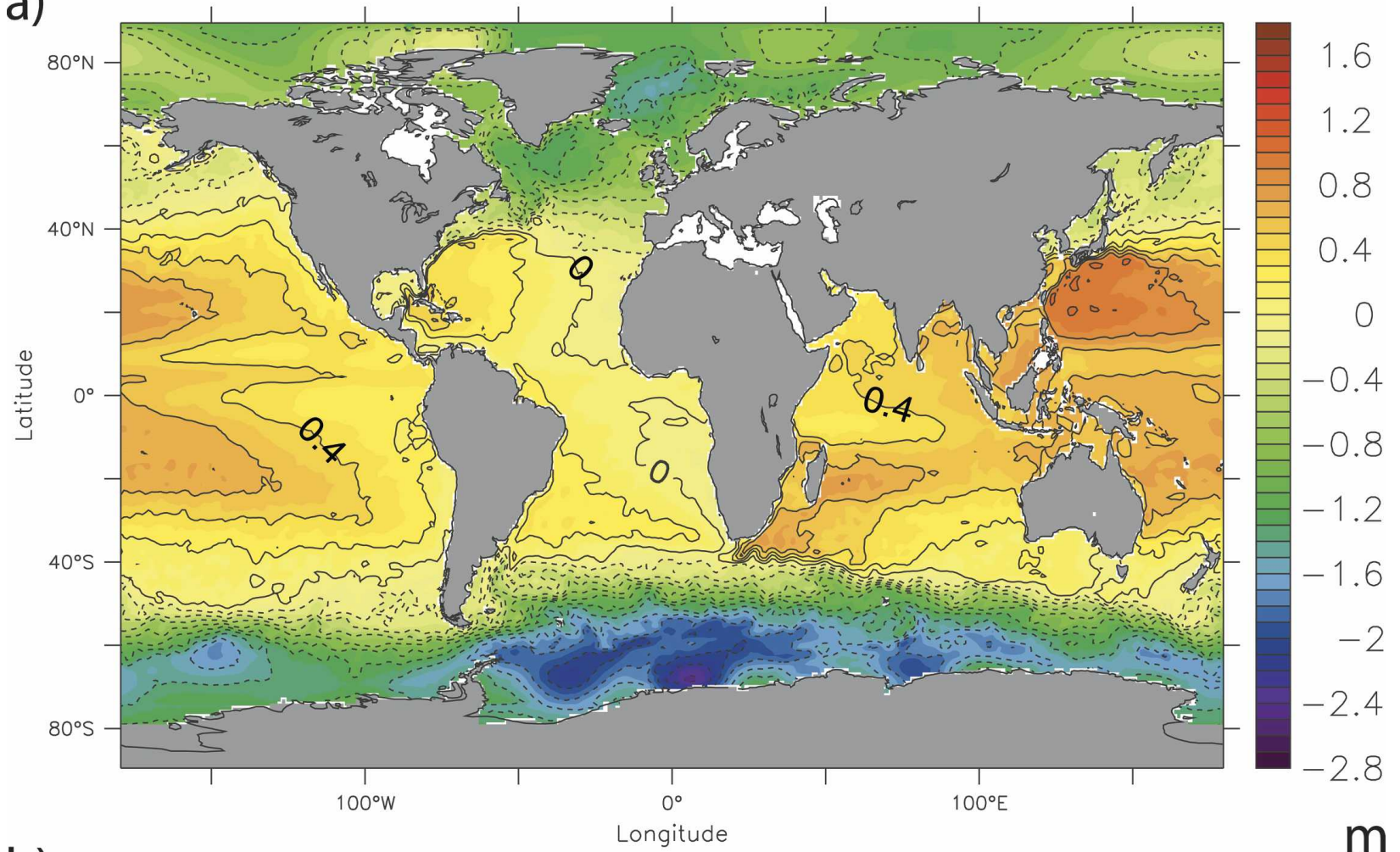

b)

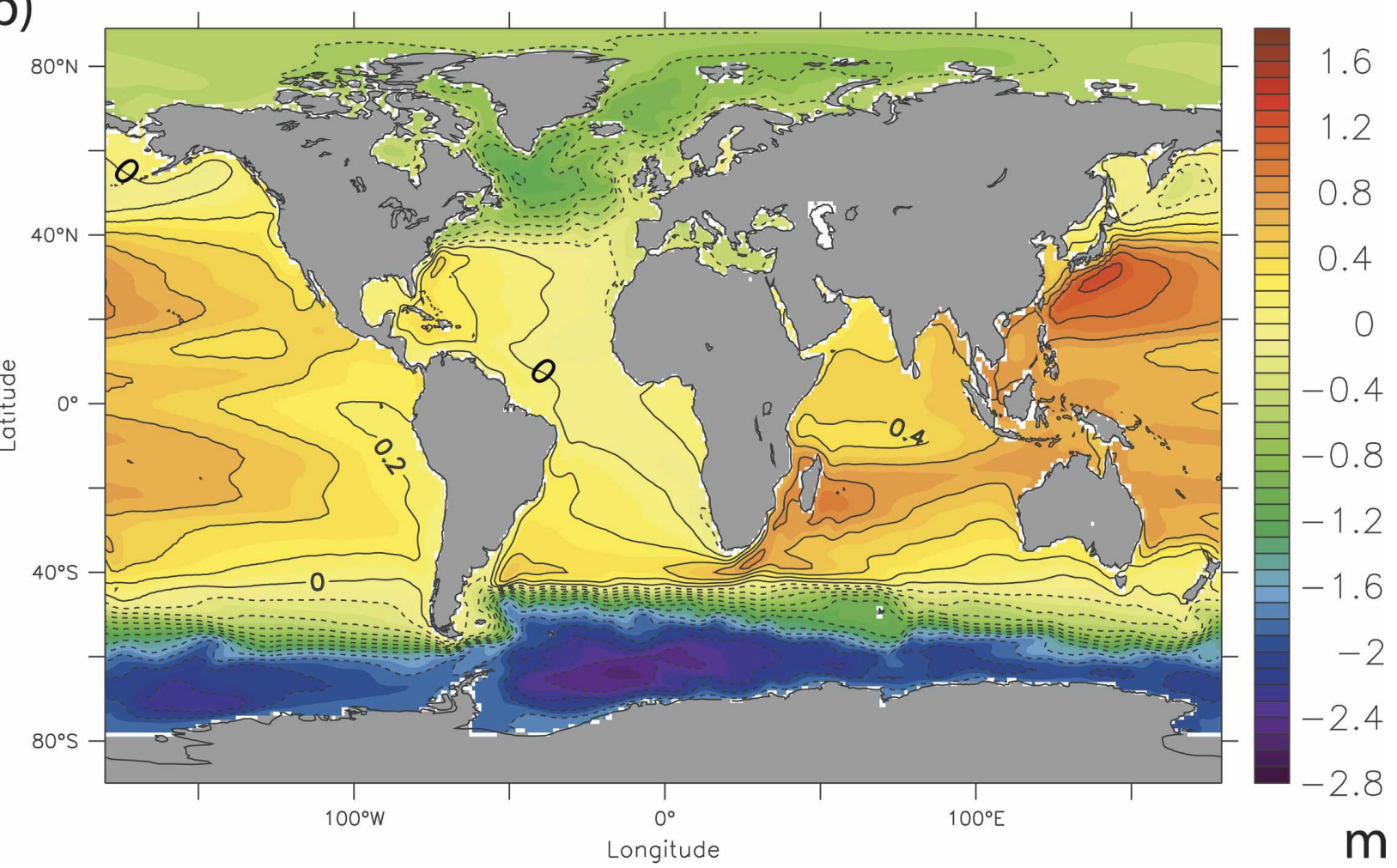

FIG. 1. Relative SSH (m): (a) CMDT-RIO03 from Rio and Hernandez (2004) and (b) mean free-surface topography from the control simulation. Both fields are adjusted to zero global mean; the contour line interval is $0.2 \mathrm{~m}$. 
etry, in situ measurements, and a geoid model for the averaging period 1993-99 (Rio and Hernandez 2004), provides a reference for the dynamic SSH pattern of MPI-OM. The control run of MPI-OM reproduces the main SSH features well (Fig. 1b); the largest deviations between the two SSH fields occur in regions of strong currents with high spatiotemporal variability, such as the Gulf Stream, Kuroshio, and South Atlantic subpolar gyre. The relative sea level difference between the North Atlantic and North Pacific averaged from $40^{\circ}$ to $65^{\circ} \mathrm{N}$ over each ocean basin amounts to $0.78 \mathrm{~m}$ in our control simulation, as compared with $0.72 \mathrm{~m}$ in the CMDT dataset over the same region. Since barotropic (depth averaged) and baroclinic flows determine local SSH gradients, discrepancies between our model SSH and the CMDT dataset arise from insufficiently or inaccurately resolved dynamics in MPI-OM. The North Atlantic Current follows the $45^{\circ} \mathrm{N}$ latitude band across the Atlantic in our simulations. It is thus located too far south and is too zonal in comparison with observations, an issue that is most likely linked to insufficient topographic resolution (Jungclaus et al. 2006). Furthermore, one formation site of NADW in MPI-OM is located in the southern Labrador Sea, whereas the observed NADW formation takes place farther north in the Labrador basin. Deep convection areas are manifested in SSH maps as local minima due to the high density; hence, observed and modeled SSH minima in the North Atlantic do not coincide (Figs. 1a and 1b). In the Southern Hemisphere, the simulated mass flux of $165 \mathrm{~Sv}$ (Sv $\equiv 10^{6} \mathrm{~m}^{3} \mathrm{~s}^{-1}$ ) through Drake Passage (Jungclaus et al. 2006) is more than observational estimates of 118-140 Sv (e.g., Whitworth et al. 1982). The SSH gradient from the South Atlantic across the ACC is too steep when compared with observations (Figs. 1a and 1b). This is caused by the cyclonic Weddell Sea gyre, which appears to be too strong in MPI-OM (Jungclaus et al. 2006). Uncertainties in the observed SSH in high-latitude regions (above $\approx 65^{\circ}$ ) are still relatively large, since satellite altimetry is not available and coverage with hydrographic profiles in the polar regions is comparatively poor (Rio and Hernandez 2004).

The control integration yields a mean of $19.1 \pm 1.1 \mathrm{~Sv}$ for the simulated maximum Atlantic MOC at $30^{\circ} \mathrm{N}$. This compares to observational estimates of $18 \pm 4 \mathrm{~Sv}$ (Macdonald 1998), $18 \mathrm{~Sv}$ (Talley 2003), and $15 \pm 2 \mathrm{~Sv}$ (Ganachaud and Wunsch 2000). Maximum global poleward heat transports in MPI-OM reach 1.8 PW near $26^{\circ} \mathrm{N}$ in the Northern Hemisphere, and $-1.7 \mathrm{PW}$ near $10^{\circ} \mathrm{S}$ in the Southern Hemisphere. For the Atlantic basin, the simulated heat transport of $1.15 \mathrm{PW}$ at $20^{\circ} \mathrm{N}$ is slightly lower than the $1.27 \pm 0.15 \mathrm{PW}$ derived from in-

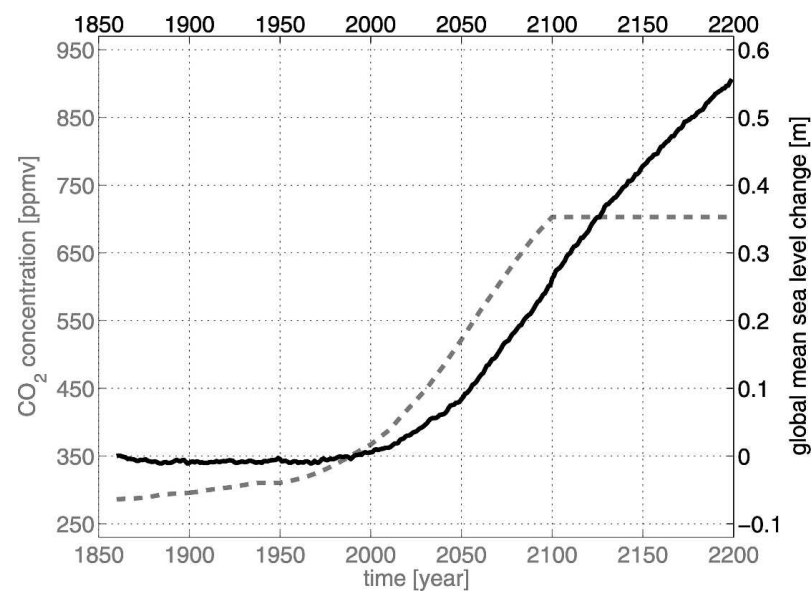

FIG. 2. Gray line: atmospheric $\mathrm{CO}_{2}$ concentration in the twentieth century (1860-2000), the A1B scenario simulation (20012100), and for the period afterward (2101-99). Black line: global mean sea level rise in response to the prescribed $\mathrm{CO}_{2}$ forcing.

verse calculations by Ganachaud and Wunsch (2003). The simulated sea ice extent and its seasonal variation compares favorably to observations (Jungclaus et al. 2006).

Coupled models that do not apply any flux adjustments have deficiencies because of insufficient resolution and/or unresolved processes. In ECHAM5/MPIOM, deep ocean drift and a lack of Antarctic Bottom and Intermediate Water formation appear to be the most relevant challenges for the simulation of sea level changes (Jungclaus et al. 2006). We will show, however, that the simulated climate change signals are robust features. Within the constraints and limitations mentioned, we are thus confident that there is a certain amount of "realness" to our results.

\section{c. Model scenario response}

Our analysis is based upon a realization of an IPCC scenario simulation. The coupled experiments were conducted with transient greenhouse gas concentrations and aerosol forcing from preindustrial to presentday values for the period from 1860 to 2000 ("twentieth century"), followed by the IPCC Special Report on Emission Scenarios (SRES) A1B scenario (Houghton et al. 2001) with increasing trace gases and aerosol concentrations from 2001 until 2100. The simulations are then extended for another $100 \mathrm{yr}$ with greenhouse gas concentrations fixed at the 2100 level; for example, $\mathrm{CO}_{2}$ is at 703 ppmv (Fig. 2). This prescribed forcing leads to global mean surface temperature anomalies of $1.7^{\circ} \mathrm{C}$ by $2040-60$, and $3.4^{\circ} \mathrm{C}$ by $2080-2100$ in the A1B scenario. A transient $1 \% \mathrm{CO}_{2}$ increase simulation with the same model configuration as ECHAM5/MPI-OM yields an 
effective climate sensitivity of $\sigma_{\text {eff }}=0.83 \mathrm{~K} \mathrm{~W}^{-1} \mathrm{~m}^{-2}$ (E. Roeckner 2005, personal communication).

The MOC in the North Atlantic shows no trend in the twentieth-century simulation but does exhibit multidecadal variability with amplitudes between 18 and 24 Sv. After the year 2000, however, the Atlantic MOC at $30^{\circ} \mathrm{N}$ gradually decreases by $25 \%$ from its initial mean strength of 19 to $14.5 \mathrm{~Sv}$ at the end of the twenty-first century. The mechanisms that determine the MOC response to greenhouse gas forcing involve air-sea buoyancy fluxes and the advection of salt and temperature anomalies in the ocean (Thorpe et al. 2001). Consequently, a change in ocean circulation pattern and intensity causes a massive redistribution of water mass properties, resulting in significant differences of regional sea level responses. The adjustment of regional $\mathrm{SSH}$ will be the focus of our analysis and is described in detail in section 3 .

There is only little change until 1960, and global mean sea level then rises slowly until 2010 (Fig. 2). It then strongly accelerates in the twenty-first century, rising to a total of $0.26 \mathrm{~m}$ by 2100 . This implies that the net heat flux into the ocean is increasing steadily (Gregory et al. 2001). Global sea level continues to rise an additional $0.30 \mathrm{~m}$ from 2100 to 2199 at stabilized GHG concentrations because of the large heat capacity of the oceans, which continue to take up heat and hence expand (Meehl et al. 2005), albeit at a slightly decreasing rate (quadratic fit of the control run subtracted; by subtracting the control from the scenario simulation to obtain anomalies, we implicitly assume a linear separability of drifts).

Based on in situ temperature observations from pentadal composites for the 1955-59 through 1994-98 period for the 0-3000-m layer, the global thermosteric linear trend is $0.40 \pm 0.05 \mathrm{~mm} \mathrm{yr}^{-1}$ (Antonov et al. 2005 ), corresponding to a heat input of $14.5 \times 10^{22} \mathrm{~J}$ (Levitus et al. 2005). Our simulation yields a similar global sea level trend of $0.34 \pm 0.09 \mathrm{~mm} \mathrm{yr}^{-1}$ for the same period, but a considerably lower net heat increase of $8.1 \times 10^{22} \mathrm{~J}$. The underestimate of heat uptake might be linked to the too warm deep and intermediate waters in MPI-OM (see section 2b), with the more efficient thermal expansivity at higher temperatures causing a similar global mean sea level rise somewhat by chance. Apart from seasonal variations, Antonov et al. (2005) also observed the decadal variability of ocean heat storage and, thus, thermosteric sea level change. Church et al. (2005) linked volcanic eruptions with significant decadal variability of ocean heat content and global mean sea level (up to $3 \times 10^{22} \mathrm{~J}$ and $5 \mathrm{~mm}$, respectively); our simulation does not include volcanic forcing and, thus, cannot represent this effect.
A particularly large climate response occurs in the Arctic Ocean in our simulation: it becomes largely ice free during the summer by 2070, reducing the total annual mean arctic sea ice volume gradually from $3 \times 10^{4}$ $\mathrm{km}^{3}$ to less than $1 \times 10^{4} \mathrm{~km}^{3}$. We give an order of magnitude estimate of the effects of the inferred freshening to the halosteric anomaly in the Arctic Ocean in section 4.

The analysis presented in the following sections is based on annual mean values. Since we are interested in the transient changes under the SRES-A1B scenario, seasonal variability, which is mostly due to air-sea heat and freshwater exchange that affects the upper 100 to $200 \mathrm{~m}$ of the water column, is not considered.

\section{Spatial pattern of SSH adjustments}

In this section, we describe and explain SSH changes in the aforementioned scenario integration. The meridional $\mathrm{SSH}$ gradient in the Atlantic basin has been associated with the strength of the Atlantic MOC (Thorpe et al. 2001). Another perspective was introduced earlier by Bryan (1996), who described a distinct dipole pattern of sea level change in the western North Atlantic, which he inferred to be consistent with a weakening of the upper branch of the Atlantic MOC once an allowance is made for changes induced by the wind-driven circulation. Decadal variability of SSH in the western North Atlantic has been proposed to reflect predominantly overturning changes through the topographic coupling between depth-averaged and baroclinic flows (Häkkinen 2001). As Gregory et al. (2001) in their analysis of previous IPCC results have pointed out, most simulated regional sea level changes differed significantly from the global average, but there was a considerable lack of agreement about the distribution of these regional patterns between various models, with only two robust exceptions: first, a maximum increase of sea level in the Arctic Ocean from enhanced freshwater input, and second, a minimum reduction of sea level in the Southern Ocean. In the open ocean basins, where geostrophy holds, the change of local- and basinscale sea level gradients is a direct measure of largescale circulation changes (Gregory et al. 2001); hence, discrepancies in local sea level change between different model simulations are caused by differences in large-scale circulation patterns and deep-water formation rates. This, in turn, directly determines the local water mass properties and, hence, the steric response through temperature and salinity changes. We will elaborate on this point in section 4. Here, we will first describe the global pattern of dynamic sea level changes, and then compare regional SSH features with relevant oceanic circulation indices. For the time period 


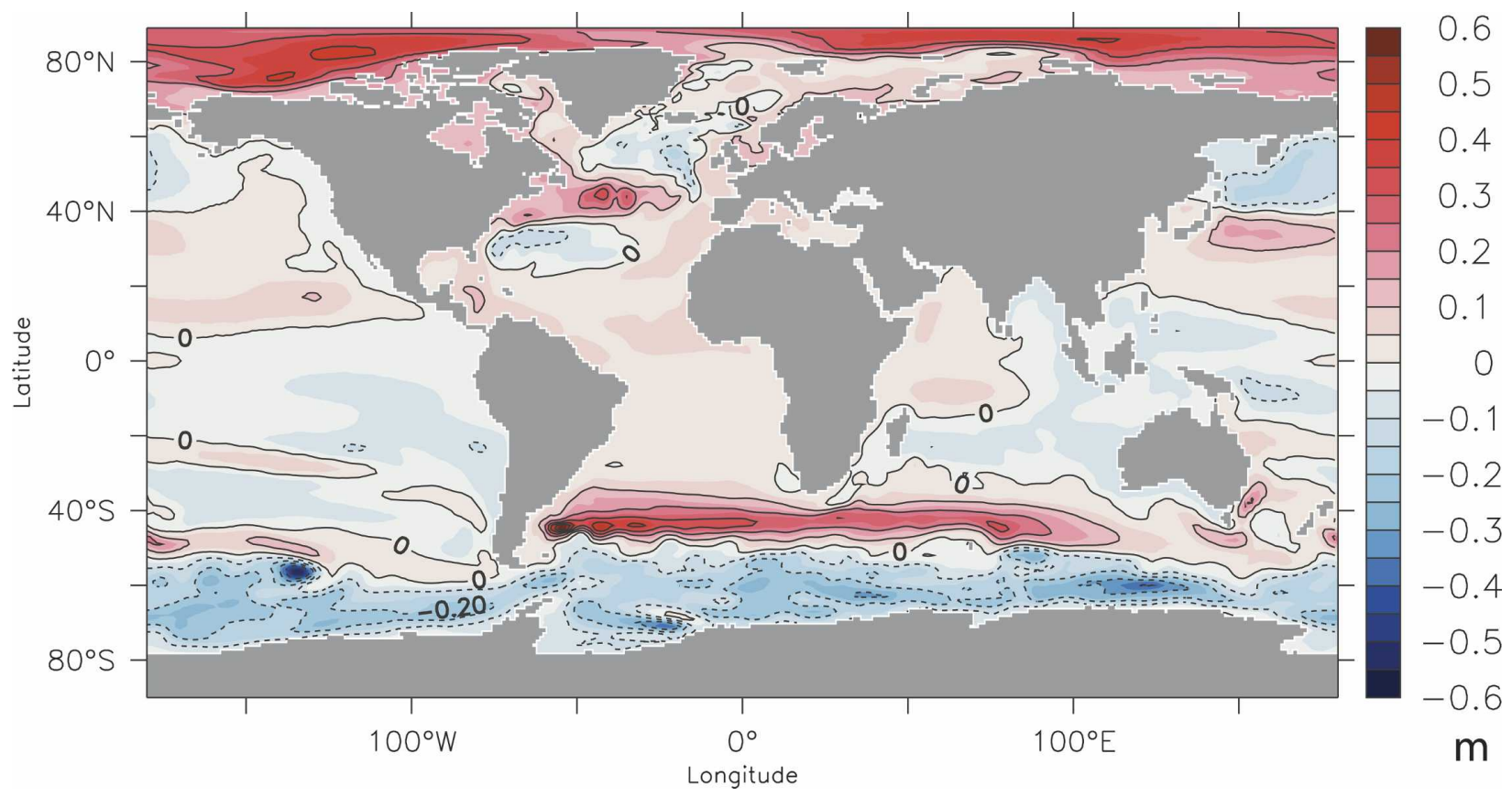

FIG. 3. MPI-OM SSHA (m): relative difference between the mean SSH for the decade 2090-99 and the control run mean SSH (Fig. 1b); contour line interval is $0.1 \mathrm{~m}$. Global mean changes (Fig. 2) are not included and must be added to obtain the full sea level change.

2090-99, relative to the control simulation and zero global mean, local extreme amplitudes of regional sea level change range from -0.53 to $+0.6 \mathrm{~m}$ (Fig. 3); maximum basin-scale changes amount to $\pm 0.3 \mathrm{~m}$ in Arctic Ocean and Southern Ocean (see Fig. 4b below). These values do not include the global mean sea level rise (Fig. 2, section 2c), which must be added to obtain the full sea level signal.

The most prominent pattern in the North Atlantic resembles a tripole in SW-NE orientation: $\mathrm{SSH}$ is lower by up to $0.15 \mathrm{~m}$ in the central subtropical area, is higher by $0.4 \mathrm{~m}$ along the path of the North Atlantic drift, and is lower again farther north in the central part of the subpolar gyre. This pattern is consistent with a northward shift of the North Atlantic Current by some $6^{\circ}$, which is evident from the shift of near-surface horizontal velocities (not shown). Along the eastern and western coastlines of the Atlantic basin, dynamic sea level increases everywhere between 0.05 and $0.15 \mathrm{~m}$. From $30^{\circ} \mathrm{S}$ to $10^{\circ} \mathrm{N}$ in the Atlantic, $\mathrm{SSH}$ changes by less than $0.05 \mathrm{~m}$; these changes are nearly uniform, so that the relative SSH gradients between these latitudes are not altered (Fig. 3). In the Indian and Pacific Oceans, dynamic SSH generally changes by not more than $0.05 \mathrm{~m}$. An exception is the Kuroshio and its extension, where a dipole pattern (Fig. 3) indicates an increasing SSH gradient, consistent with a stronger horizontal mass transport in this region (not shown). In contrast to the North Atlantic Current, however, the Kuroshio ex- tension does not shift in latitude. Sea level in the Arctic Ocean increases by up to $0.4-0.5 \mathrm{~m}$ toward the end of the twenty-first century (Fig. 3). This is nearly twice the global average, and, as will be shown in section 4, is mainly due to freshening of the surface layers from increased precipitation and river runoff. The basinaverage gradient from the Arctic Ocean to the North Atlantic basin increases by $0.2 \mathrm{~m}$ accordingly (Fig. 4), and the total freshwater export from the Arctic Ocean through Fram Strait and the Canadian Arctic Archipelago rises by $50 \%$ (H. Haak 2005, personal communication); across Bering Strait, the SSH drop is reduced by $0.3 \mathrm{~m}$, but the direction of the gradient is maintained, and freshwater import (referenced to a salinity of $S_{\text {ref }}=$ $34.8 \mathrm{psu}$ ) into the Arctic Ocean through Bering Strait actually increases by $20 \%$ during the twenty-first century (H. Haak 2005, personal communication). The meridional SSH difference across the ACC increases from a zonal average of 2.6 to $2.8 \mathrm{~m}(+7 \%)$, which can be associated with a stronger transport of the ACC (e.g., Drake Passage transport increases by $6 \%$ from 160 to $170 \mathrm{~Sv})$. In the Atlantic and Indian Ocean sections of the ACC, the SSH gradient increases from 2.6 to $2.92 \mathrm{~m}$ $(+11 \%)$ (Fig. 3). We relate this prominent pattern to a strengthening of the combined gyre transport of the anticyclonic South Atlantic subtropical gyre and the cyclonic Weddell Sea gyre. Both gyres contribute about equally to the anomalous transport by purely baroclinic contributions (not shown). 

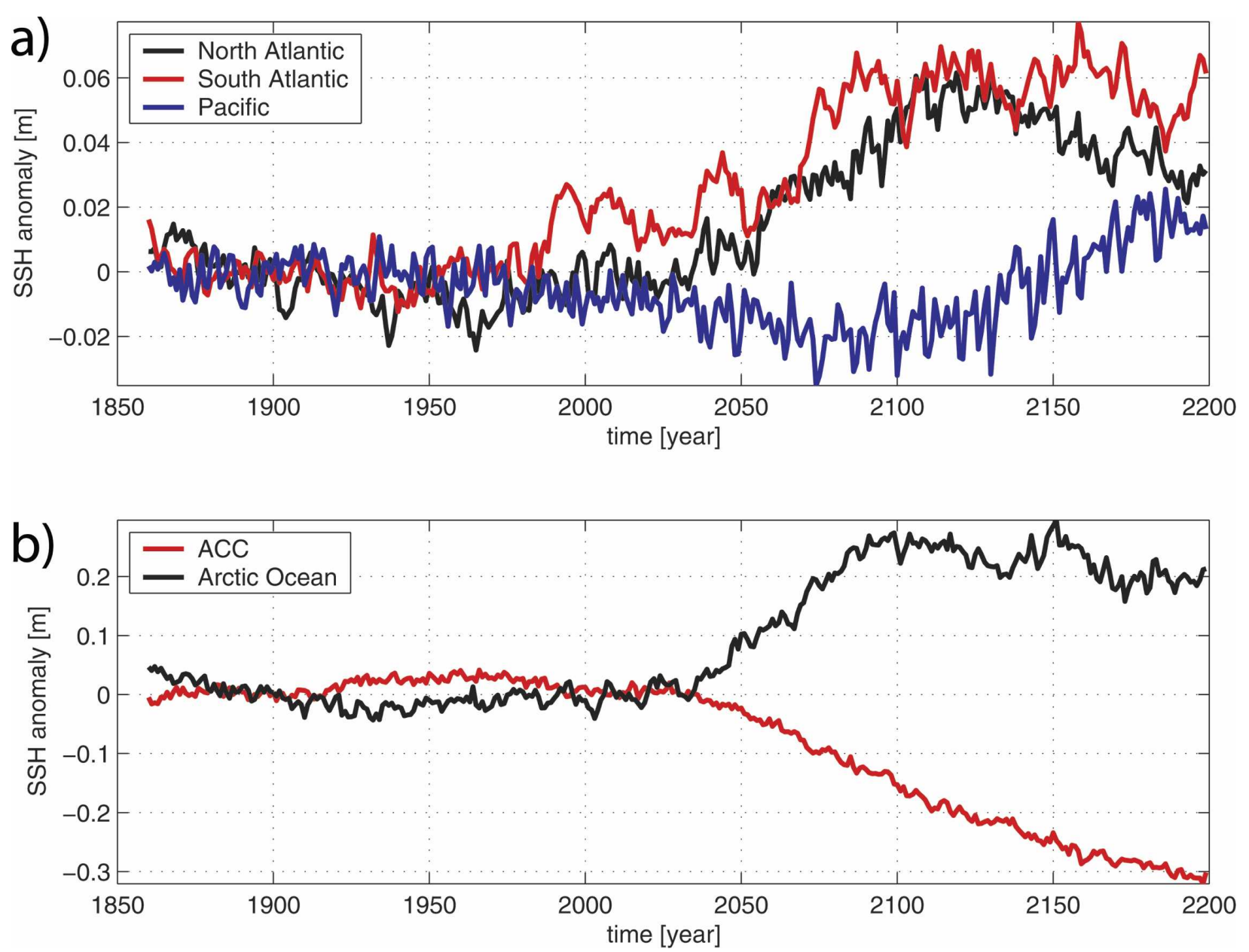

FIG. 4. Basin-averaged evolution of SSH anomalies: deviation from the global mean change in Fig. 2 at corresponding times: (a) North Atlantic $\left(0^{\circ}-65^{\circ} \mathrm{N}\right)$, South Atlantic $\left(40^{\circ} \mathrm{S}-0^{\circ}\right)$, and Pacific $\left(30^{\circ} \mathrm{S}-65^{\circ} \mathrm{N}\right) \mathrm{SSH}$ and (b) ACC $\left(80^{\circ}-55^{\circ} \mathrm{S}\right)$ and Arctic Ocean $\left(75^{\circ}-90^{\circ} \mathrm{N}\right) \mathrm{SSH}$. Note that vertical scales in (a) and (b) are different.

The temporal development of regional integrated relative SSH anomalies (Fig. 4) illustrates that the time scales of basin-integrated SSH adjustments are not uniform (note that the mean global sea level rise from Fig. 2 must be added to the curves in Fig. 4 to obtain the full sea level change). Basin-averaged SSHs in the North and South Atlantic exhibit a pronounced multidecadal variability, with maximum rates of change near $15 \mathrm{~mm}$ $\mathrm{yr}^{-1}$. Toward 2120, relative SSH in the Atlantic basin has risen by $60 \mathrm{~mm}$ in both hemispheres, so that the South to North Atlantic SSH gradient remains largely unchanged. Note, however, that the variability of North and South Atlantic basin-integrated SSH is different. Several modeling studies have empirically found a linear relationship between interhemispheric meridional steric height (or pressure) gradients and the meridional overturning circulation (Hughes and Weaver 1994; Thorpe et al. 2001; Hu et al. 2004a). This requires a simple relation between zonal and meridional pressure gradients. In the light of an equatorially asymmetric thermohaline flow, however, the theoretical connection between zonal and meridional pressure gradients is not straightforward (Marotzke 1997, 2000; Marotzke and Klinger 2000). Whereas it is conceptually plausible that a change in Atlantic overturning is connected to NADW properties and thus also to the meridional density gradient, it is not so obvious how the spatially structured sea surface topography would adjust to MOC changes. It is also apparent from Fig. 3 that a simple "subpolar area up-subtropical area down" pattern, similar to the North Atlantic dipole mentioned by Bryan (1996), is not applicable in the present simulation.

In the Pacific, basin-averaged SSH shows a small negative trend in the twenty-first century, followed by a small positive trend in the twenty-second century (Fig. 
4); the relative difference between North Atlantic and Pacific Ocean SSH (section 2b) thus reaches a minimum value synchronously with the minimum of the North Atlantic MOC around the year 2100 (see Fig. 5 below). From 2100 to 2199, this SSH difference has been almost reestablished (within $0.02 \mathrm{~m}$ ), but without an analog recovery of the North Atlantic MOC. The strongest relative SSH changes occur in the high latitudes: basin-average Arctic Ocean SSH has increased $0.25 \mathrm{~m}$ by 2100 , while SSH in the Southern Ocean decreases uniformly through the twenty-first and twentysecond centuries, not reaching equilibrium during the simulation period. Additional transient $1 \% \mathrm{CO}_{2}$ increase experiments, using a coarser-resolution version of ECHAM5/MPI-OM with separated atmospheric heat fluxes and wind forcing, indicate that the prominent SSH anomaly signal along the South AtlanticACC front can be attributed to anomalous wind forcing, without a subsequent change of North Atlantic overturning (not shown); thus, the South Atlantic SSH signal in the present simulation has most likely no predictive skill for the North Atlantic MOC.

What are the implications of this complex SSH adjustment for the large-scale circulation patterns? Since the driving mechanisms in the present scenario simulation are a complex interplay of anomalous wind forcing, freshwater, and heat fluxes, we do not expect to find a simple linear relationship between sea level changes in the North Atlantic and MOC strength. This is in contrast to the analysis by Levermann et al. (2005), who applied a 0.35 -Sv freshwater equivalent negative salt flux for $800 \mathrm{yr}$ to invoke a shutdown of the North Atlantic overturning cell. To assess the connection between the baroclinic components of the North Atlantic subtropical and subpolar gyre circulations and SSH changes, we have calculated potential energy anomalies (PEAs) from the temperature and salinity fields following the procedure of Curry and McCartney (2001). The PEA $\chi$ is defined as the vertical integral of the specific volume anomaly $\delta$ over the top $2000 \mathrm{dbar}$, multiplied by pressure $p$ and divided by the gravitational constant $g$ :

$$
\chi=\frac{1}{g} \int_{p}^{0} p \delta d p
$$

PEA $\left(\mathrm{J} \mathrm{m}^{-2}\right)$ is similar to dynamic height, but weighted by $\mathrm{pg}^{-1}$, and approximates a streamfunction for the baroclinic mass transport. The choice of $2000 \mathrm{dbar}$ for the lower level of integration was made here to be consistent with Curry and McCartney (2001). An index of the baroclinic mass transport $\left(10^{6} \mathrm{~kg} \mathrm{~s}^{-1}=1 \mathrm{MT} \mathrm{s}^{-1}\right.$, which is equal to $10^{6} \mathrm{~m}^{3} \mathrm{~s}^{-1}=1 \mathrm{~Sv}$ within a few percent) between two locations is then obtained by the PEA difference, divided by a mean Coriolis parameter $f$ :

$$
T_{m}=\frac{\chi_{1}-\chi_{2}}{f} .
$$

Estimates from the climatological PEA difference between Bermuda (box averaged from $30^{\circ}$ to $35^{\circ} \mathrm{N}$ and $63^{\circ}$ to $68^{\circ} \mathrm{W}$ ) and the Labrador Sea (box averaged from $53^{\circ}$ to $58^{\circ} \mathrm{N}$ and $45^{\circ}$ to $50^{\circ} \mathrm{W}$ ) yield an mean eastward baroclinic mass transport of $60 \mathrm{MT} \mathrm{s}^{-1}$ (Curry and McCartney 2001) between the two centers, using $f$ at $40^{\circ} \mathrm{N}$. This compares to an average combined NA subtropical-subpolar gyre transport of $74.2 \mathrm{MT} \mathrm{s}^{-1}$ in our unperturbed control integration, with a maximal change of $\approx 21 \mathrm{MT} \mathrm{s}^{-1}$ between transport extremes, and pronounced multidecadal variability (Fig. 5a, gray line).

In the scenario simulation, the mean gyre transport index is reduced to $\approx 68 \mathrm{MT} \mathrm{s}^{-1}$ by the year 2100 (Fig. 5a, black line), and the mean transport from 2100 to 2199 resides around this value. Labrador Basin and Bermuda PEA both increase considerably under the A1B scenario from the year 2000 on; based on the individual PEA gyre histories (not shown), we conclude that the transport reduction between 2060 and 2100 (Fig. 5a) can be mainly attributed to more rapid changes in the Labrador Basin PEA in this period. The sea surface height difference $\triangle \mathrm{SSH}$ calculated between the same Labrador Basin and Bermuda boxes compares well to the gyre transport index in terms of interannual variability (Fig. 5b). However, while the gyre transport reduces over the course of $40 \mathrm{yr}$, the SSH difference reduces by $0.15 \mathrm{~m}$ around 2070 in less than 5 yr. Curiously, this SSH change is mainly caused by a 0.11-m SSH drop in the Bermuda box, and only a 0.04-m SSH change in the Labrador Basin box. We are currently unable to explain this very rapid adjustment in Bermuda SSH; note, however, that this signal is on the order of magnitude of internal variability. The variability in the North Atlantic gyre transport has been partly linked to the atmospheric North Atlantic Oscillation (NAO) index (Curry and McCartney 2001); the NAO index in the present simulation does indeed coincide with positive and negative NA gyre transport extremes of 6-7 Sv between 1890 and 1940 (not shown), pointing to the importance of wind-driven gyre transport anomalies. For the remaining simulation period, however, there is little agreement between the atmospheric and oceanic indexes. Most importantly, the gyre transport shift from 2060 to 2100 is not accompanied by a similar regime shift in the NAO index, which does not show a significant corresponding trend. Thus, we focus our analysis here on the connection between the combined baroclinic gyre transport, $\Delta \mathrm{SSH}$, and MOC in the North Atlantic.

The maximum of the Atlantic MOC at $30^{\circ} \mathrm{N}$ weakens 

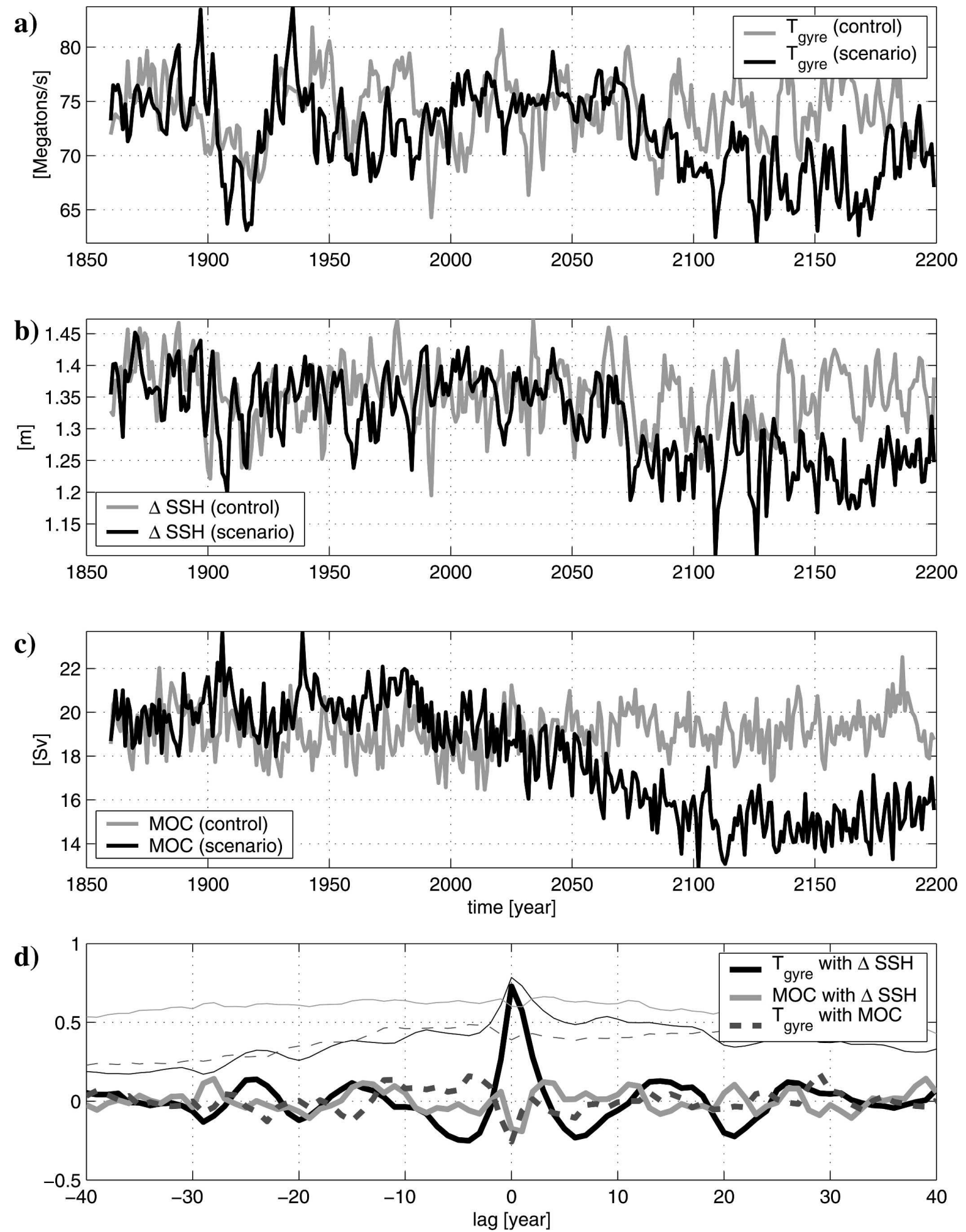

FIG. 5. (a) The NA baroclinic gyre transport index as defined in Curry and McCartney (2001). (b) The $\Delta$ SSH between Bermuda and the Labrador Sea. (c) The NA MOC at $30^{\circ}$ N. (d) Lag correlation of the scenario time series [black lines in (a)-(c)] with each other. The thin lines in (d) are calculated from the A1B scenario time series as shown above [black lines in (a)-(c)]; the thick lines in (d) are calculated from the same A1B scenario time series but with 21-yr running means subtracted to remove the longer-period trends. 
gradually, beginning as early as in the year 2000, reaching its minimum value of $14.5 \mathrm{~Sv}$ (a $26 \%$ reduction) around the year 2100 , followed by a modest recovery to $16 \mathrm{~Sv}$ in the remaining 100 simulation years (Fig. 5c). Significant changes in the combined gyre transport, however, set in around year 2070 (Fig. 5a); the weakening MOC during the years 2000-70 does not appear to affect the gyre transport index during this period. Choosing a different latitude for the MOC index does not alter the picture qualitatively. Although the horizontal gyre circulation is related to the MOC through coupling between the barotropic and baroclinic modes through topography (Häkkinen 2001), it is apparent (Figs. 5a and 5c) that the MOC and combined gyre circulation evolve differently not only in terms of interannual to decadal variability, but also in terms of largescale circulation changes that are associated with a reduction of the North Atlantic overturning rate.

We have calculated a simple lag correlation (Fig. 5d) between the normalized time series of gyre transport, $\Delta$ SSH, and MOC. The apparent trends between 2000 and 2199 in all time series (from the scenario calculation) dominate the correlation values (thin lines in Fig. $5 d$ ), yielding little information on shorter time scales. The effect of this trend has been removed by subtracting 21-yr running means from the original time series, and calculating correlations with the detrended time series (thick lines in Fig. 5d). The correlation of the gyre transport index with the dynamic SSH difference between Bermuda and Labrador at zero lag is 0.78 for the detrended and 0.73 for the original time series, respectively (Fig. 5d). The high correlation between gyre transport and $\Delta \mathrm{SSH}$ at zero lag furthermore indicates that surface velocities can be used to infer the baroclinic part of the combined gyre transport from the surface to 2000-dbar depth, and SSH changes pertain mainly to transport anomalies in this layer. MOC anomalies are not significantly correlated with either $\Delta \mathrm{SSH}$ or the gyre transport on time scales of less than 21 yr (Fig. 5d), effectively preventing reliable estimates of MOC strength on these time scales from $\Delta \mathrm{SSH}$ as defined here. Perhaps, a simple, linear relationship between SSH changes and MOC reduction is masked in the present study because of the interference of a number of processes in the North Atlantic. Furthermore, the MOC as a zonally integrated quantity represents basin-scale changes that need not necessarily be present in those locations that we chose for the gyre transport calculations. Analyzing Ocean Topography Experiment (TOPEX)/Poseidon altimeter observations, Häkkinen (2001) and Häkkinen and Rhines (2004) reported that SSH in the North Atlantic subpolar gyre increased during the 1990s, indicating a weaker subpolar gyre circulation through the balance of SSH anomalies with geostrophic velocity anomalies. As far as a decline of the baroclinic subpolar gyre circulation originates from local air-sea buoyancy forcing, gyre transport anomalies could also point to a cessation of deep convection processes, which in turn are intimately linked to the MOC strength (Häkkinen and Rhines 2004).

In our analysis, we have avoided smoothing of the time series in Figs. 4 and 5. All time series exhibit annual to decadal variability, which appears to be of internal origin. Sufficient smoothing would certainly bring out the GHG signal more clearly and, thus, lead to higher correlation between gyre transport, $\Delta \mathrm{SSH}$, and the MOC (Fig. 5d). However, our comparison of combined gyre transport, $\triangle \mathrm{SSH}$, and MOC suggests that inferences of the MOC state in the NA from SSH anomalies are difficult, especially on time scales of less than $20 \mathrm{yr}$, where internal climate variability prevents a skillful correlation between gyre transport, $\Delta \mathrm{SSH}$, and the MOC.

\section{Thermosteric and halosteric SSH changes}

In this section, we describe the global pattern of steric sea level changes under the applied IPCC-A1B scenario. Steric sea level change is associated with vertical expansion or contraction of the water column in response to changes in the local density structure, and the total mass of the global ocean is kept constant (our simulation does not include eustatic contributions from land sources). We frame our discussion in terms of variations (with respect to time, indicated by a prime) from a mean or control state of the vertically integrated hydrostatic balance, as in Gill and Niiler (1973). The deviation of the sea surface elevation $\zeta^{\prime}$ is then the sum of three terms:

$$
\zeta^{\prime}=\zeta_{a}^{\prime}+p_{b}^{\prime} g^{-1} \rho_{0}^{-1}+\zeta_{s}^{\prime}
$$

where $\zeta_{a}^{\prime}$ is the barometric correction to sea level, $p_{b}^{\prime} g^{-1} \rho_{0}^{-1}$ is the contribution from bottom pressure changes, and $\zeta_{s}^{\prime}$ is defined as the steric level deviation,

$$
\zeta_{s}^{\prime}=-\int_{-H}^{0} \frac{\rho^{\prime}}{\rho_{0}} d z
$$

where $\rho_{0}$ is usually referenced to a temperature of $0^{\circ} \mathrm{C}$ and a salinity of $35 \mathrm{psu}$. In the present analysis, $\zeta_{a}^{\prime}=0$. Equation (4) implies that the dynamic sea surface height and steric height (or, analogous, their horizontal gradients) are only equivalent if bottom pressure changes are zero. Otherwise, the flow field calculated 


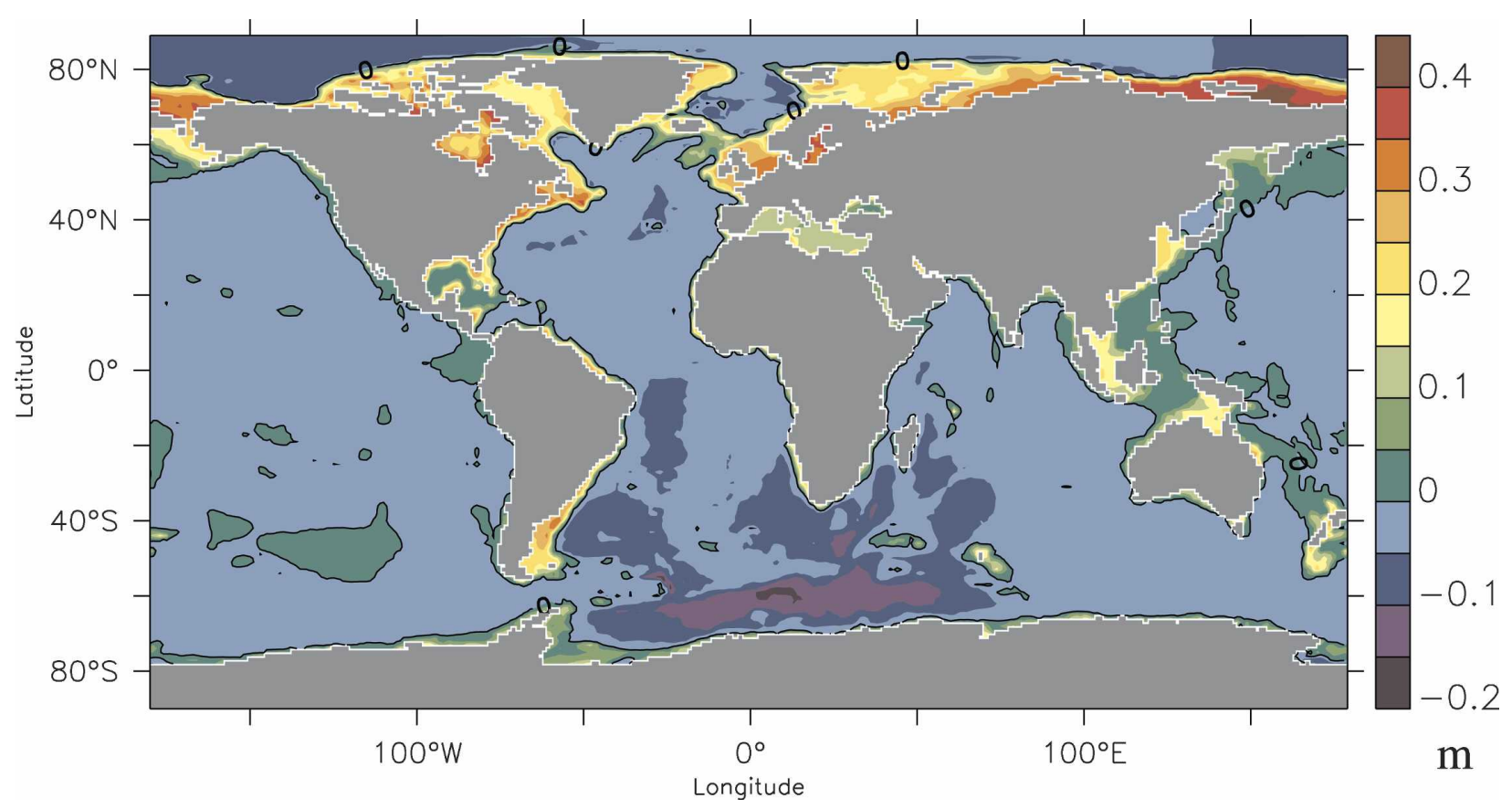

FIG. 6. Mean bottom pressure changes $p_{b}^{\prime} g^{-1} \rho_{0}^{-1}$ ( $\mathrm{m}$ water column equivalent) for the decade 2090-99 relative to the control simulation, as defined in Eq. (4).

through the geostrophic relation is not physically acceptable, as it fails to conserve mass in the presence of a nonzero vertically averaged background flow (Wunsch and Stammer 1998). From the difference between the dynamic ( $\zeta^{\prime}$ : prognostically calculated as described in section 2) and steric [ $\zeta_{s}^{\prime}$ : from Eq. (5)] sea level fields, we obtain the bottom pressure changes for the period 2090-99 relative to the control run mean (Fig. 6). As the model does not include eustatic sources, all bottom pressure changes occur solely because of mass redistribution within the global ocean. Most prominently, all shelf regions (less than $\approx 500 \mathrm{~m}$ depth) experience an additional mass loading of up to $0.45 \mathrm{~m}$ (Fig. 6). The very shallow water columns only permit a purely steric expansion much smaller than that of deepwater columns. The resulting strong steric SSH gradients across shelves cannot be balanced by geostrophy; instead, a mass redistribution $\left[p_{b}^{\prime} g^{-1} \rho_{0}^{-1}\right.$ term in Eq. (4)] onto the shelves occurs, effectively reducing the total gradient in sea level across the shelves. Another salient feature is the pronounced negative bottom pressure anomaly of up to $0.2 \mathrm{~m}$ in the Atlantic section of the Southern Ocean, which we relate to the intensified gyre circulation as described in section 3.

From Eq. (4), we evaluate the individual contribution of temperature and salinity to the steric anomalies in reference to the temperature and salinity fields of the unperturbed control integration. These thermosteric $\left(\zeta_{s}^{\text {thermo }}\right)$ and halosteric $\left(\zeta_{s}^{\text {halo }}\right)$ sea level changes are then calculated from

$$
\begin{gathered}
\zeta_{s}^{\text {thermo }}=\int_{-H}^{0} \frac{\rho\left(S_{C}, T_{C}, p\right)-\rho\left(S_{C}, T_{\mathrm{EX}}, p\right)}{\rho\left(S_{C}, T_{C}, p\right)} d z \quad \text { and } \\
\zeta_{s}^{\text {halo }}=\int_{-H}^{0} \frac{\rho\left(S_{C}, T_{C}, p\right)-\rho\left(S_{\mathrm{EX}}, T_{C}, p\right)}{\rho\left(S_{C}, T_{C}, p\right)} d z
\end{gathered}
$$

where the subscripts EX and $C$ refer to the scenario experiments and control run fields, respectively, and the in situ density $\rho$ is a time-dependent, nonlinear function of salinity, temperature, and pressure (Gill 1982). Combining the two different temperature and salinity fields from the control and scenario experiments potentially introduces an error in the density calculation through nonlinearity in the equation of state. However, we have computed the difference between the full steric height field and the sum of the two individual fields, and found that the deviation is at least two orders of magnitude smaller than the actual steric signals (not shown).

For the period 2090-99, the mean thermosteric sea level change is positive for most regions in all oceans (Fig. 7). In the Southern Hemisphere, a few isolated patches in the Pacific and Southern Oceans have a negative thermosteric anomaly; in the Northern Hemi- 
a)

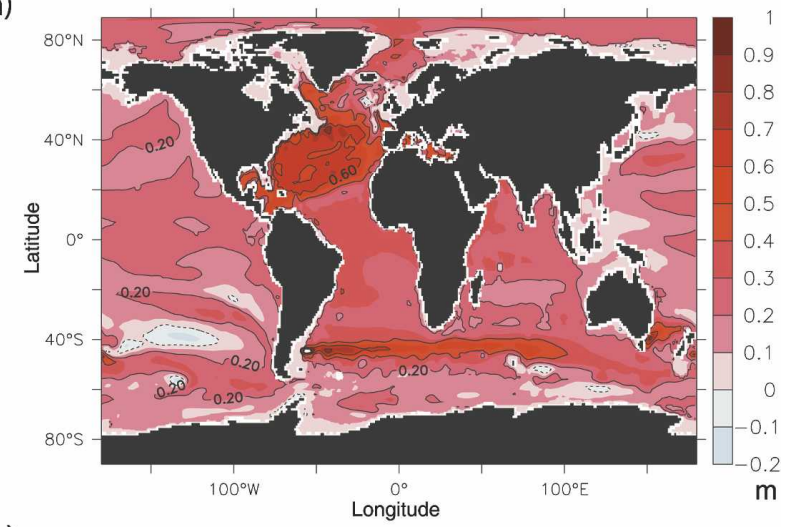

b)

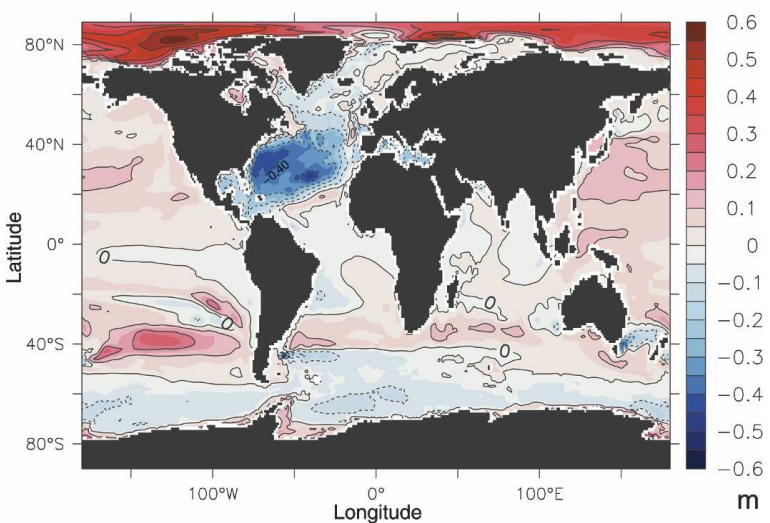

c)

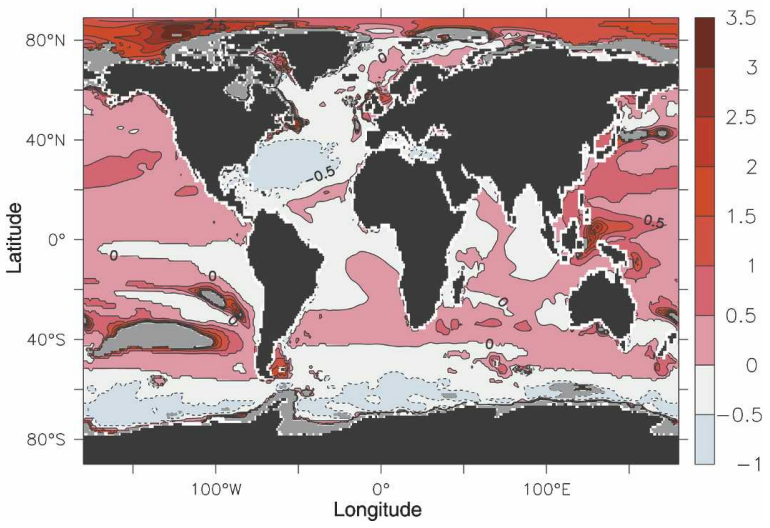

FIG. 7. Steric sea level difference for the period 2090-99 relative to the control run, as defined in Eq. (6). (a) Thermosteric ( $\zeta_{s}^{\text {thermo }}$ ) contribution, (b) halosteric ( $\zeta_{s}^{\text {halo }}$ ) contribution, and (c) ratio $\zeta_{s}^{\text {halo } /}$ $\zeta_{s}^{\text {thermo }}$, with values above 3.5 and below -1 in gray.

sphere, two small negative anomalies are located in the North Atlantic subpolar gyre and north of the Kuroshio. The eastern part of the subpolar NA gyre responds with a minimum thermosteric sea level rise. The thermosteric sea level change in the North Atlantic basin and along the South Atlantic edge of the ACC is largely above $0.55 \mathrm{~m}$, which is significantly stronger than in the Pacific at comparable latitudes, where values mostly do not exceed $0.25 \mathrm{~m}$. Such differing re- sponses reflect the formation of deep water and enhanced ventilation, by which the warming signal can penetrate to the deeper layers in those regions, and then be advected horizontally.

Considerable redistribution of salt within and between ocean basins has been observed over annual to decadal periods (Levitus 1990), leading to significant halosteric anomalies on regional scales Antonov et al. (2002). Here, we will focus our analysis on transient local salinity changes and the implied halosteric signal under the A1B scenario. As expected, the sign of the halosteric sea level signal is alternating between the different ocean basins (Fig. 7b). We find the most pronounced signals in the subtropical North Atlantic and in the Arctic Ocean, which exhibit a similar absolute halosteric sea level change of $0.5 \mathrm{~m}$, but with negative and positive signs, respectively (Figs. $7 \mathrm{~b}$ and $7 \mathrm{c}$ ). The Pacific basin shows a small net increase (with local maxima around $0.1 \mathrm{~m}$ ) reflecting increased freshwater import from the Atlantic basin (Latif et al. 2000), and in the Antarctic Ocean the halosteric change is slightly negative (with minima around $-0.15 \mathrm{~m}$ ). What are the origins of the simulated halosteric expansion and contraction? Regional salinity changes are a consequence of changes in the local freshwater balance, for example, induced by changes in the hydrological cycle (precipitation, evaporation, and river runoff: $P-E+R$ ), anomalous salt advection in the ocean, or altered sea ice volume. Increased atmospheric moisture transport from lower to high latitudes is a common feature of many climate scenario simulations (Bryan 1996; Mikolajewicz and Voss 2000; Thorpe et al. 2001), and can account for the large negative salinity anomaly in the Atlantic subtropical region and the positive salinity anomaly in the Arctic Ocean. For the Arctic Ocean, an additional positive halosteric source is melting sea ice. Relative to the twentieth century, some additional $7.8 \times 10^{4} \mathrm{~km}^{3}$ freshwater have been put into the Arctic Ocean through $P-E+R$ changes by the end of the twenty-first century, while melting sea ice contributes about $1.8 \times 10^{4} \mathrm{~km}^{3}$ of anomalous freshwater. If we assume, for the sake of argument, that these freshwater anomalies simply replace existing Arctic waters, a maximum of $20 \%$ of the halosteric anomaly in the Arctic Ocean by 2090-99 can be attributed to disappearing sea ice. Curry and Mauritzen (2005) found a freshening of the Nordic Seas and subpolar basins in the Atlantic between 1965 and 1995 in the upper $1000 \mathrm{~m}$. This would imply a positive halosteric signal. In our A1B simulation, the halosteric signal in this region changes sign from positive (fresher) to negative (saltier) around 2040, indicating that a net negative freshwater balance prior to 2040 is then converted in sign and dominated 
by salt advection from the subtropical NA. Thorpe et al. (2001) suggested that this mechanism might also function as a stabilizing feedback for the MOC in the Atlantic.

Last, we consider the vertical structure of the steric signals. Starting at the sea surface, the thermosteric and halosteric contributions from each level are cumulatively summed up to a depth of $3000 \mathrm{~m}$ for different ocean subdomains for the period 2090-99 (Fig. 8). Generally, the thermosteric signal is larger than any halosteric change, with the exception of the Arctic Ocean. There, the freshening of the $0-250-\mathrm{m}$ layer contributes about $55 \%$ to the total steric sea level change, whereas the deeper layers from 250 to $1500 \mathrm{~m}$ mainly add to the thermosteric signal (Fig. 8e). This subsurface warming of the Arctic Ocean under increasing GHG forcing is due to increased northward heat transport north of $\approx 60^{\circ} \mathrm{N}$, similar to the anomalous advection mechanism described by $\mathrm{Hu}$ et al. (2004b). Despite the reduced MOC, subtropical and subpolar Atlantic water masses still modulate the deeper Arctic Ocean layers significantly in our simulation. This is in contrast to an earlier study of (Bryan 1996), who found that the reduction of the overturning in the Atlantic would isolate the Arctic Ocean from the warmer and saltier subtropical Atlantic water masses. In the Atlantic, halosteric and thermosteric changes tend to compensate each other, but the thermosteric signal is 1.5-3 times as strong as any halosteric change (Figs. 8a and 8b). Because of deepwater formation, the thermosteric expansion in the subpolar North Atlantic is very homogeneous up to the depth of NADW $(\approx 2000 \mathrm{~m})$, whereas the thermosteric signal in the subtropical North Atlantic has its largest contribution within the upper $1000 \mathrm{~m}$. The Pacific response is much smaller in amplitude, and the steric changes are largely confined to the upper $500-700 \mathrm{~m}$ (Figs. $8 \mathrm{c}$ and $8 \mathrm{~d}$ ). In the Southern Ocean, thermo- and halosteric changes occur over the entire depth range of 0-3000 m (Fig. 8f). This demonstrates the intense vertical transfer in the ACC, by which the water properties are changed throughout the water column. Notice the reversal of the halosteric change at a depth of $200 \mathrm{~m}$ from positive (fresher) to negative (saltier) in the Southern Ocean. The response in the upper layers is likely linked to the increased atmospheric moisture transport from low to high latitudes (similar to the change in the Arctic Ocean freshwater balance), whereas the deeper-layer changes are most likely influenced by saltier upwelling NADW (cf. to Fig. 8a). Qualitatively, the differences in the vertical extent of thermosteric changes between ocean basins agree well with recent observations from Barnett et al. (2005), who find that the vertical structure of a warming signal, penetrating the oceans since 1960 , varies widely by ocean.

Our results show that salinity anomalies have a significant influence on regional steric sea level changes. Among others, Antonov et al. (2002) have pointed out that estimates of heat content or temperature changes from altimetry can be seriously biased for certain regions, when halosteric effects are not considered. It will become increasingly more important to take salinity changes into account beyond their natural variability in the evaluation of regional and global sea level changes. One may also view this as a problem of hydrographic versus altimetric measuring systems.

\section{Conclusions}

Based on our analysis of dynamic and steric sea surface height (SSH) changes in the IPCC A1B scenario as simulated with ECHAM5/MPI-OM, we conclude the following.

1) We confirm previous results that global sea level change is not an accurate measure of regional sea level change in simulated climate change scenarios, because regional sea level anomalies are of a similar order of magnitude (Figs. 2 and 4). Possible eustatic sources for sea level change are not considered in this study.

2) We also confirm previous results that basin-integrated SSH adjustments yield the strongest increase in the Arctic Ocean from enhanced freshwater input from precipitation and river runoff; $\mathrm{SSH}$ changes are minimal in the Southern Ocean as a result of increased wind stress, which leads to a stronger ACC transport and a subsequent dynamic SSH adjustment.

3) The basin-integrated SSH difference of $0.78 \mathrm{~m}$ between the North Atlantic and Pacific Oceans is reduced by $0.06 \mathrm{~m}$ by the year 2100 , coinciding with a minimum North Atlantic overturning, but is reestablished within 100 yr through a Pacific Ocean SSH rise and a North Atlantic SSH drop, without an ana$\log$ recovery of the North Atlantic overturning.

4) The sea surface height difference between Bermuda and the Labrador Sea correlates highly at zero lag with the combined North Atlantic gyre transport on interannual to decadal time scales. Overturning changes in the North Atlantic, on the other hand, evolve on different time scales, and cannot be reliably inferred from SSH gradient and gyre transport changes.

5) Mass redistribution within the global ocean by 2090 99 causes bottom pressure increases of up to $0.45 \mathrm{~m}$ across shallow shelf areas; the Atlantic section of the 

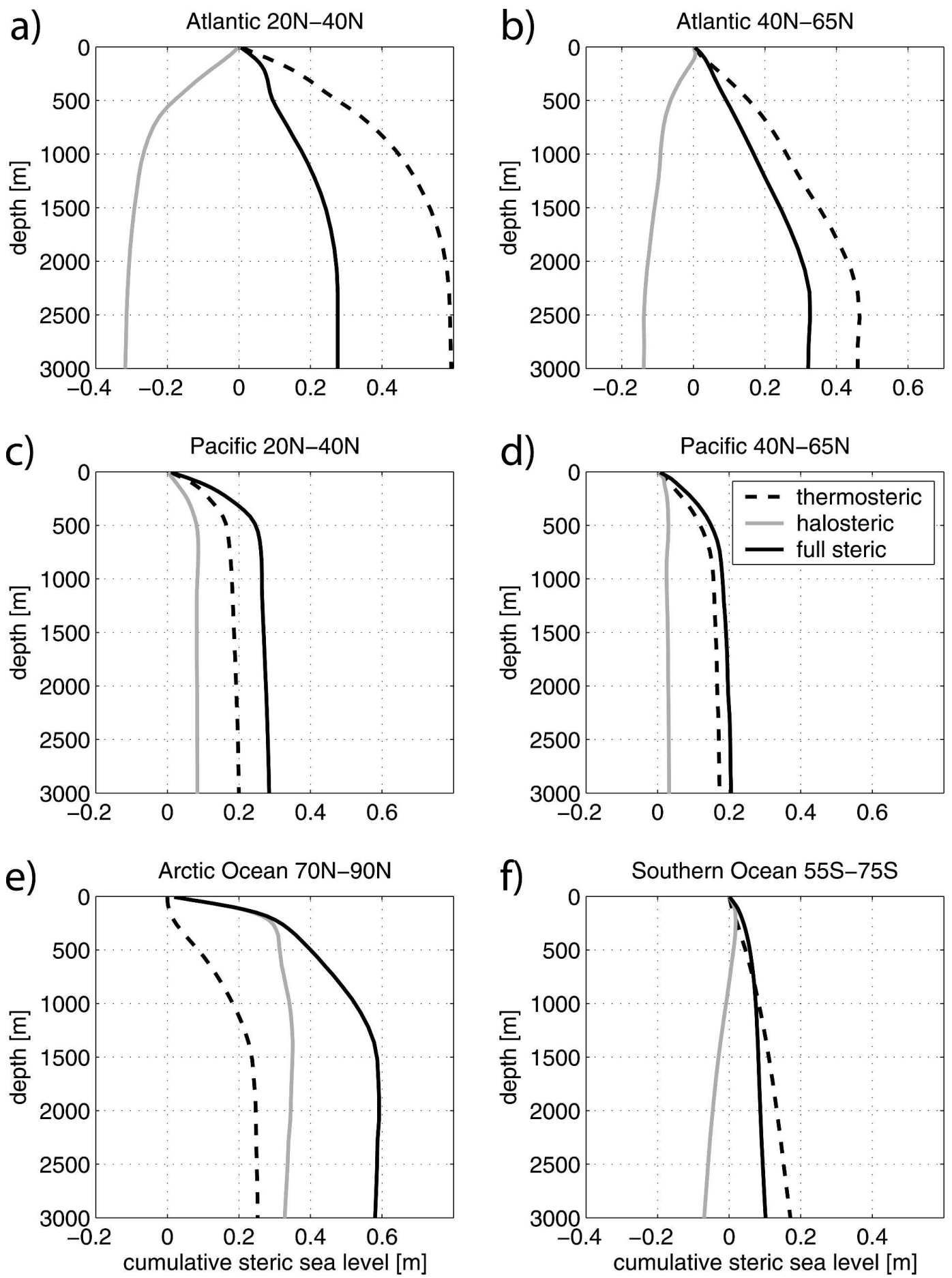

FIG. 8. Cumulative sum of thermosteric (dashed line), halosteric (gray line), and total steric (black line) anomalies for different ocean areas. Starting at the surface, the steric anomaly from each depth layer is added up. Note that the abscissa has the same width in all plots.

ACC responds with a negative bottom pressure anomaly of up to $-0.2 \mathrm{~m}$ due to the intensified gyre circulation. It remains to be analyzed how these large-scale mass redistributions would affect the geoid: for example, changes of the earth's dynamic oblateness $\left(J_{2}\right)$ and regional isostatic adjustment.

6) Thermosteric sea level change by 2100 is positive in almost all ocean regions but varies considerably by 
region. Halosteric effects in the North Atlantic subtropical region partly compensate thermosteric sea level rise. In contrast, freshening in the Arctic Ocean leads to an additional halosteric sea level rise. Steric anomalies in the Pacific Ocean are positive, but of smaller magnitude.

7) The vertical distribution of thermosteric and halosteric anomalies that contribute to sea level change is very different between ocean basins. In the North Atlantic, the steric anomalies reach to depths of the North Atlantic Deep Water (2000 m), whereas steric anomalies in the entire Pacific Ocean occur mainly in the upper $500 \mathrm{~m}$. In the Southern Ocean, steric anomalies occur throughout the entire water column, reflecting the strong vertical exchange of buoyancy in this region.

Acknowledgments. Sea level has, arguably, been the dominant theme among Carl Wunsch's many and widespread scientific interests. Ironically, this is the first paper any of us has written on sea level. Moreover, between us we have only ever coauthored a single paper with Carl, apart from two later group efforts. And yet, one of us (JM) has been closely associated with Carl for over 15 years, beginning with a two-year period as a postdoctoral student at MIT. This only seeming paradox demonstrates Carl's generosity in at least two ways. He has fostered the growth of junior scientists by inspiring them and helping them gain independence immediately thereafter. But he has also been ready to find every scientific idea worth considering as long as it is new, even if it does not fit into one of his established interests. Thus, we are very proud to contribute our very first sea level paper to this special issue.

Johanna Baehr provided valuable comments on the manuscript. We thank Uwe Mikolajewicz and Detlef Stammer for stimulating discussions. We thank M.-H. Rio for providing the CMDT-RIO03 dataset and two anonymous reviewers for their very constructive comments and suggestions. This work was supported by the Max Planck Society and the International Max Planck Research School on Earth System Modelling. The computer simulations were performed at the DKRZ (Deutsches Klimarechenzentrum) in Hamburg, Germany.

\section{REFERENCES}

Antonov, J. I., S. Levitus, and T. P. Boyer, 2002: Steric sea level variations during 1957-1994: Importance of salinity. J. Geophys. Res., 107, 8031, doi:10.1029/2001JC000964.

, - - and - 2005: Thermosteric sea level rise, 1955-2003. Geophys. Res. Lett., 32, L12602, doi:10.1029/2005GL023112.

Barnett, T. P., D. W. Pierce, K. M. Achutarao, P. J. Gleckler, B. D. Santer, J. M. Gregory, and W. M. Washington, 2005:
Penetration of human-induced warming into the world's oceans. Science, 309, 284-287.

Bryan, K., 1996: The steric component of sea level rise associated with enhanced greenhouse warming: A model study. Climate Dyn., 12, 545-555.

Cazenave, A., and R. S. Nerem, 2004: Present-day sea level change: Observations and causes. Rev. Geophys., 42, RG3001, doi:10.1029/2003RG000139.

Church, J. A., N. J. White, and J. M. Arblaster, 2005: Significant decadal-scale impact of volcanic eruptions on sea level and ocean heat content. Nature, 438, 86-89.

Curry, R. G., and M. S. McCartney, 2001: Ocean gyre circulation changes associated with the North Atlantic Oscillation. $J$. Phys. Oceanogr., 31, 3374-3400.

_ , and C. Mauritzen, 2005: Dilution of the northern North Atlantic Ocean in recent decades. Science, 308, 1772-1774.

Ganachaud, A., and C. Wunsch, 2000: Improved estimates of global ocean ciculation, heat transport and mixing from hydrographic data. Nature, 408, 453-457.

—, and - 2003: Large-scale ocean heat and freshwater transports during the World Ocean Circulation Experiment. $J$. Climate, 16, 696-705.

Gill, A. E., 1982: Atmosphere-Ocean Dynamics. International Geophysics Series, Academic Press, 662 pp.

— and P. P. Niiler, 1973: The theory of the seasonal variability in the ocean. Deep-Sea Res., 20, 141-177.

Greatbatch, R. J., 1994: A note on the representation of steric sea level in models that conserve volume rather than mass. $J$. Geophys. Res., 99, 12 767-12 771.

Gregory, J. M., and Coauthors, 2001: Comparison of results from several AOGCMs for global and regional sea-level change 1900-2100. Climate Dyn., 18, 225-240.

_ , H. T. Banks, P. A. Stott, J. A. Lowe, and M. D. Palmer, 2004: Simulated and observed decadal variability in ocean heat content. Geophys. Res. Lett., 31, L15312, doi:10.1029/ 2004GL020258.

Hagemann, S., and L. Dümenil, 1998: A parameterization of the lateral waterflow for the global scale. Climate Dyn., 14, 17-31.

Häkkinen, S., 2001: Variability in sea surface height: A qualitative measure for the meridional overturning in the North Atlantic. J. Geophys. Res., 106, 13 837-13 848.

— circulation during the 1990s. Science, 304, 555-559.

Houghton, J. T., Y. Ding, D. J. Griggs, M. Noguer, P. J. van der Linden, and D. Xiaosu, Eds., 2001: Climate Change 2001: The Scientific Basis. Cambridge University Press, 944 pp.

Hu, A. X., G. A. Meehl, and W. Q. Han, 2004a: Detecting thermohaline circulation changes from ocean properties in a coupled model. Geophys. Res. Lett., 31, L13204, doi:10.1029/ 2004GL020218.

,-- W. M. Washington, and A. Dai, 2004b: Response of the Atlantic thermohaline circulation to increased atmospheric $\mathrm{CO}_{2}$ in a coupled model. J. Climate, 17, 4267-4279.

Hughes, T. M. C., and A. J. Weaver, 1994: Multiple equilibria of an asymmetric two-basin ocean model. J. Phys. Oceanogr., 24, 619-637.

Jungclaus, J. H., and Coauthors, 2006: Ocean circulation and tropical variability in the coupled model ECHAM5/MPIOM. J. Climate, 19, 3952-3972.

Knutti, R., and T. F. Stocker, 2000: Influence of the thermohaline circulation on projected sea level rise. J. Climate, 13, 19972001. 
Latif, M., E. Roeckner, U. Mikolajewicz, and R. Voss, 2000: Tropical stabilization of the thermohaline circulation in a greenhouse warming simulation. J. Climate, 13, 1809-1813.

Levermann, A., A. Griesel, M. Hoffmann, M. Montoya, and S. Rahmstorf, 2005: Dynamic sea level changes following changes in the thermohaline circulation. Climate Dyn., 24, 347-354.

Levitus, S., 1990: Interpentadal variability of steric sea-level and geopotential thickness of the North-Atlantic Ocean, 19701974 versus 1955-1959. J. Geophys. Res., 95, 5233-5238.

— J. I. Antonov, T. P. Boyer, and C. Stephens, 2000: Warming of the World Ocean. Science, 287, 2225-2229.

- — , and - 2005: Warming of the World Ocean, 19552003. Geophys. Res. Lett., 32, L02604, doi:10:1029/ 2004GL21592.

Macdonald, A. M., 1998: The global ocean circulation: A hydrographic estimate and regional analysis. Progress in Oceanography, Vol. 41, Pergamon, 281-382.

Marotzke, J., 1997: Boundary mixing and the dynamics of threedimensional thermohaline circulations. J. Phys. Oceanogr., 27, 1713-1728

- 2000: Abrupt climate change and thermohaline circulation: Mechanisms and predictability. Proc. Natl. Acad. Sci. USA, 97, 1347-1350

— metric thermohaline circulations. J. Phys. Oceanogr., 30, 955970.

Marsland, S. J., H. Haak, J. Jungclaus, M. Latif, and F. Röske, 2003: The Max-Planck-Institute global ocean-sea ice model with orthogonal curvilinear coordinates. Ocean Modell., 5, 91-127.

Meehl, G. A., W. M. Washington, W. D. Collins, J. M. Arblaster, A. Hu, L. E. Buja, W. G. Starnd, and H. Teng, 2005: How much more global warming and sea level rise? Science, 307, 1769-1772.

Mikolajewicz, U., and R. Voss, 2000: The role of the individual air-sea flux components in the $\mathrm{CO}_{2}$-induced changes of the ocean's circulation and climate. Climate Dyn., 16, 627-642.

- B. D. Santer, and E. Maier-Reimer, 1990: Ocean response to greenhouse warming. Nature, 345, 589-593.

Munk, W., 2002: Twentieth century sea level: An enigma. Proc. Natl. Acad. Sci. USA, 99, 6550-6555.

Reid, J. L., 1961: On the temperature, salinity, and density differences between the Atlantic and Pacific Oceans in the upper kilometer. Deep-Sea Res., 7, 265-275.

Rio, M.-H., and F. Hernandez, 2004: A mean dynamic topography computed over the World Ocean from altimetry, in situ measurements, and a geoid model. J. Geophys. Res., 109, C12032, doi:10.1029/2003JC002226.

Roeckner, E., and Coauthors, 2003: The atmospheric general circulation model ECHAM5, part I: Model description. MaxPlanck-Institute for Meteorology Tech. Rep. 349, 127 pp.

Talley, L. D., 2003: Shallow, intermediate, and deep overturning components of the global heat budget. J. Phys. Oceanogr., 33, $530-560$.

Thorpe, A. J., J. M. Gregory, T. C. Johns, R. A. Wood, and J. F. B. Mitchell, 2001: Mechanisms determining the Atlantic thermohaline circulation response to greenhouse gas forcing in a non-flux-adjusted coupled climate model. J. Climate, 14, 3102-3116.

White, N. J., J. A. Church, and J. M. Greogory, 2005: Coastal and global averaged sea level rise for 1950 to 2000. Geophys. Res. Lett., 32, L01601, doi:10.1029/2004GL021391.

Whitworth, T., W. D. Nowlin, and S. J. Worley, 1982: The net transport of Antarctic Circumpolar Current through Drake Passage. J. Phys. Oceanogr., 12, 960-971.

Willis, J. K., D. Roemmich, and B. Cornuelle, 2004: Interannual variability in upper ocean heat content, temperature, and thermosteric expansion on global scales. J. Geophys. Res., 109, C12036, doi:10.1029/2003JC002260.

Wunsch, C., and D. Stammer, 1998: Satellite altimetry, the marine geoid, and the oceanic general circulation. Annu. Rev. Earth Planet. Sci., 26, 219-253. 